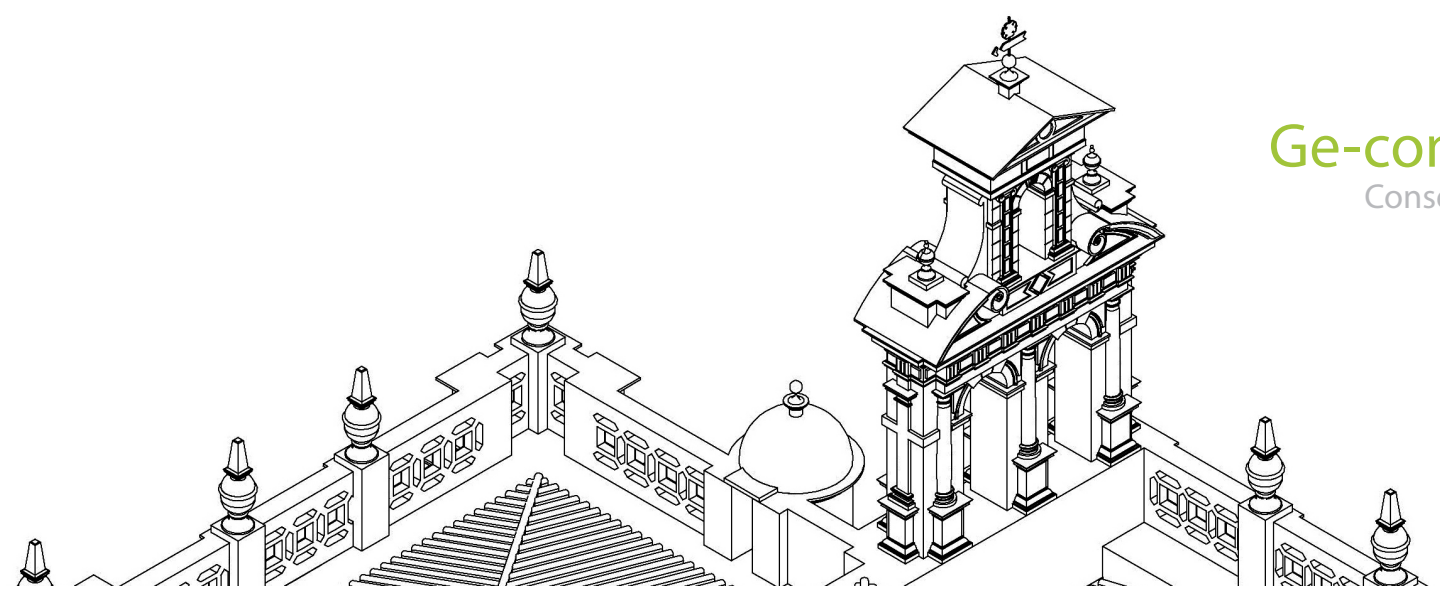

\title{
La restauración de la iglesia de Montesión en Sevilla (2002-2008)
}

\author{
Pedro Barrero Ortega
}

Resumen: En esta investigación se estudia la restauración llevada a cabo en la iglesia del exconvento dominico de Montesión en Sevilla, entre los años 2002 y 2008, bajo la dirección de los arquitectos Rafael Manzano Martos y Pedro Barrero Ortega. La iglesia, cuya autoría puede atribuirse a Hernán Ruiz II, el arquitecto cordobés que coronó la Giralda, fue desamortizada en 1835 y es actualmente propiedad del Ilustre Colegio Notarial de Andalucía. El objetivo prioritario del artículo es analizar el alcance de las intervenciones, ilustrando su estudio con fotografías y documentos gráficos elaborados para esta publicación, con el fin de darlas a conocer. Dichas intervenciones promovieron, tanto la conservación de la iglesia y otros bienes muebles, como la del Archivo de Protocolos Notariales, uno de los tesoros documentales más trascendentes para el conocimiento de la historia de la ciudad.

Palabras clave: restauración, iglesia, Montesión, Sevilla, Hernán Ruiz II, Archivo de Protocolos Notariales.

\section{The restoration of the Church of Montesión in Seville (2002-2008)}

Abstract: This research studies the restoration carried out on the church of the former Dominican convent of Montesión in Seville between 2002 and 2008, under the direction of the architects Rafael Manzano Martos and Pedro Barrero Ortega. The church, whose authorship can be attributed to Hernán Ruiz II, the Cordovan architect who crowned the Giralda, was confiscated in 1835 and is currently owned by the Illustrious College of Notaries of Andalusia. The main objective of the article is to analyse the scope of the interventions, illustrating the study with photographs and graphic documents prepared for this publication, in order to make them known. These interventions promoted the conservation of the church and other movable assets, as well as the conservation of the Archive of Notarial Protocols, one of the most important documentary treasures for the knowledge of the history of the city.

Keywords: restoration, church, Montesión, Seville, Hernán Ruiz Il, Archive of Notarial Protocols.

\section{$O$ restauro da igreja de Montesion em Sevilha (2002-2008)}

Resumo: Nesta investigação estuda-se o restauro realizado na igreja do ex-convento dominicano de Montesión em Sevilha, entre 2002 e 2008, sob a direção dos arquitetos Rafael Manzano Martos e Pedro Barrero Ortega. A igreja, cuja autoria pode ser atribuída a Hernán Ruiz II, o arquiteto cordobês que coronou a Giralda, foi desvinculada em 1835 e é atualmente propriedade do llustre Colégio Notarial da Andaluzia. O objetivo prioritário do artigo é analisar o alcance das intervenções, ilustrando o seu estudo com fotografias e documentos gráficos elaborados para esta publicação, com o fim de dá-las a conhecer. Essas intervenções promoveram, tanto a conservação da igreja e outros bens móveis, como a do Arquivo de Protocolos Notariais, um dos tesouros documentais mais transcendentes para o conhecimento da história da cidade.

Palavras-chave: restauro, igreja, Montesión, Sevilha, Hernán Ruiz Il, Arquivo de Protocolos Notariais 


\section{Introducción}

No son muchas las investigaciones y referencias bibliográficas sobre la arquitectura de la iglesia conventual de Montesión en Sevilla. Entre ellas pueden destacarse los textos de Félix González (González 1844), José Gestoso (Gestoso 1897) y Matilde Fernández (Fernández 2008), que analizan el edificio en el ámbito de estudios más generales que incluyen otros monumentos sevillanos. A partir de 1927, año en el que la iglesia pasó a ser propiedad del Colegio Notarial de Sevilla para albergar el Archivo de Protocolos Notariales, los notarios José Gastalver (Gastalver 1936) y Manuel Aguilar (Aguilar 1995), como decanos de la institución, le dedicaron sendos escritos a raíz de ese cambio de uso. Un artículo más reciente de Julia Manzano y Pedro Barrero (Manzano, Barrero 2012) analiza sus esquemas arquitectónicos, atribuyendo por primera vez su posible autoría al arquitecto Hernán Ruiz II.

El objetivo de este trabajo es analizar las restauraciones acometidas en la antigua iglesia del convento y la instalación del nuevo Archivo de Protocolos Notariales, dirigidas por los arquitectos Rafael Manzano Martos y Pedro Barrero Ortega entre 2002 y 2008. La metodología se ha basado en la consulta de fuentes bibliográficas e imágenes históricas; aportando nueva documentación gráfica, tras considerar los comentarios de Rafael Manzano, arquitecto autor del proyecto y revisar fotografías sobre las obras.

\section{Breve reseña histórica}

El convento dominico de Santa María de Montesión [Figura 1], fue fundado por iniciativa de la noble señora Doña Mencía Manuel de Guzmán. En la Biblioteca Colombina se encontró el testamento-fundación en el que se recoge que donó, a su muerte en 1559, unas casas principales que poseyó en la collación de San Juan de la Palma, en favor de Fray Martín de Mendoza, Prior Provincial de la Orden de Predicadores de Santo Domingo. En dicho documento, aparece que en "las casas principales de mi morada, que son en esta ciudad de Sevilla, en la collación de San Juan de la Palma, que lindan con casas de Diego de Barrera, Escribano público de Sevilla, se faga un monasterio y convento de catorce Frayles Sacerdotes, Confesores de la Orden de Santo Domingo y se nombre monasterio de Santa María de Montesión, en la iglesia del cual, hecho y acabado, sea trasladado mi cuerpo en la capilla mayor del dicho monasterio" (Gestoso 1897). En efecto, el 19 de junio de 1601, fueron trasladados a la capilla mayor de Montesión los restos de la fundadora, procedentes del convento dominico de San Pablo de Sevilla donde había sido enterrada, como así se recoge en la lápida conmemorativa que se encuentra en uno de los muros del presbiterio, donde hoy puede verse.

Según Gestoso, el 30 de agosto de 1576 se puso la primera piedra del convento (Gestoso 1897). Debía referirse a la primera piedra de la iglesia dado que las primeras piedras solemnes suelen corresponder a los inicios de la erección de los grandes templos conventuales.

La vida en el monasterio transcurriría según las directrices marcadas por su fundadora, hasta la llegada de la invasión napoleónica a Sevilla en 1810, fecha en la que José Bonaparte dictó un decreto por el que se ordenaba la "desaparición de todas las órdenes regulares, monacales, mendicantes y clericales". Los monjes dominicos fueron exclaustrados y saqueado el convento que, como otros de la ciudad, fue utilizado como cuartel de las tropas francesas hasta su expulsión en 1812. A partir de entonces volvió a ocuparse por los dominicos (Gestoso 1897).

Los frailes volvieron a ser expulsados en el Trienio Liberal de Fernando VII, sacándose a subasta el monasterio, sin incluir la iglesia, que le fue adjudicado en 1823 al marqués de Arco Hermoso. Aunque al retorno del absolutismo monárquico la venta fue anulada, el marqués ya había iniciado el desmontaje de uno de los claustros cuyas balaustradas llegó a colocar en su propia residencia (Fernández 2008).

La desamortización de Mendizábal de 1835 vino a desalojar definitivamente a los monjes de Santo Domingo. Durante un tiempo la iglesia mantuvo el culto, destinándose sus áreas conventuales a la fabricación de tejidos lanares. Fue en 1868 cuando la Junta Revolucionaria de la "Gloriosa" incautó el conjunto del convento con el propósito de trasladar a su iglesia la parroquial de Omnium Sanctorum, cuyo templo pretendía demolerse para la creación de una plaza, ampliando el mercado de abastos, siguiendo las tendencias higienistas de la época. No llegaron a cuajar las pretensiones aperturistas de la "Septembrina" y todo quedó abandonado. Se requisaron entonces gran parte de las obras pictóricas
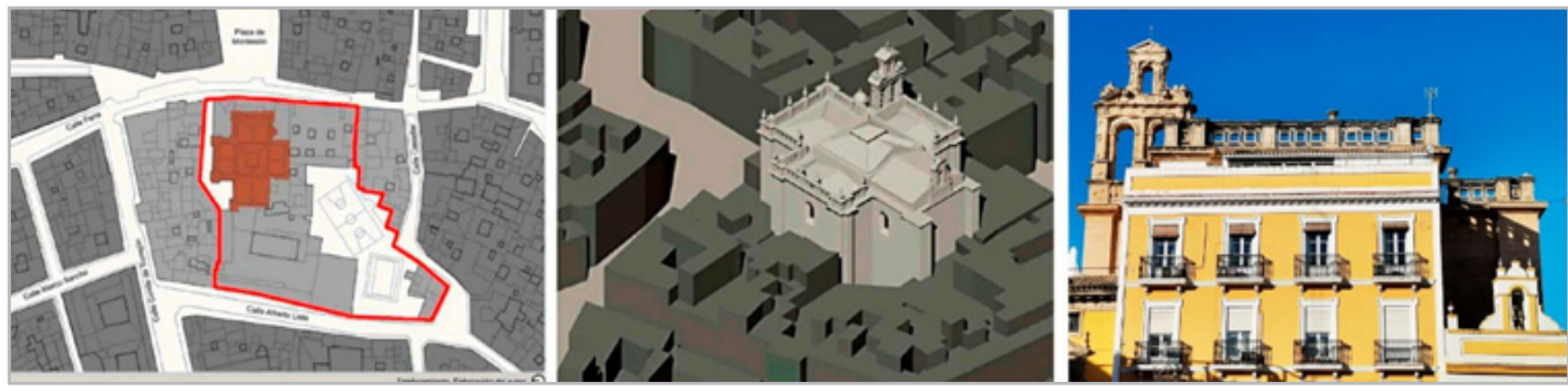

Figura 1.- Emplazamiento, maqueta virtual y vista desde la Plaza de Montesión. Dibujos y fotografía FJOG y PBO. 
del convento que fueron trasladadas al Museo de Bellas Artes de Sevilla, que había sido inaugurado oficialmente en el antiguo convento de la Merced Calzada en 1841.

En 1885, se acomodaron en Montesión las monjas de la comunidad cisterciense de Santa María de las Dueñas, cuyo convento también había sido desamortizado. Tras unas obras de rehabilitación, en las que se perdieron "...la inscripción sepulcral de la fundadora y un apreciable escudo de los Guzmanes...", quedaron definitivamente instaladas (Gestoso 1897). Las religiosas de la orden se trasladaron en 1909 al convento de Santa Inés. El 5 de agosto de 1927, el Colegio Notarial de Sevilla, representado por su decano D. José Gastalver Gimeno, adquirió la propiedad de la iglesia del antiguo convento, a fin de adecuarla, junto a otras de sus construcciones anexas, para Archivo de Protocolos Notariales de Sevilla (Gastalver 1936).

\section{Descripción de la iglesia}

La iglesia responde a un arquetipo renacentista, sin precedentes conocidos en la ciudad, de planta cruciforme $y$, aunque descrita con forma de cruz latina en la escritura de compraventa, se asemeja a la cruz griega, levemente más desarrollado el brazo de la nave principal. Su anomalía radica en que normalmente estos templos respondían a la tradición medieval de las órdenes mendicantes, que suelen tener nave única al objeto de acoger al mayor número de fieles a los pies del púlpito [Figura 2].

Según González de León, "era una de las más hermosas de la ciudad", y se resolvía mayoritariamente con una excelente fábrica de ladrillos con molduras y apilastrados resueltos con piedra arenisca procedente de la Sierra de San Cristóbal, con la que también se labró la Catedral de Sevilla (González 1844).

Su autoría puede atribuirse a Hernán Ruiz"el Joven", segundo de esta dinastía de artistas, que coronó la Giralda con su definitivo cuerpo de campanas (Manzano y Barrero 2012). Hernán Ruiz fue Maestro Mayor del Arzobispado de Sevilla, hasta su muerte acaecida el 13 de abril de 1569. Se piensa que fue Asencio de Maeda, llegado a Sevilla desde Granada, quien pudo ser el continuador de la obra del tracista inicial de la iglesia de Montesión.

La iglesia es bastante elemental y reduce su orden mural apilastrado a los ángulos del crucero, cuyos cuatro arcos fajones subdividen el espacio en cinco tramos. Dicho orden se decora con un cajeado, carente de pedestal y rematado con un capitel dórico con un entablamento muy comprimido. Los muros, labrados de ladrillo, son absolutamente lisos y todos los brazos de la cruz se cierran con bóvedas vaídas de complejas "labores para decorar bóvedas". Las de la nave principal se adornan con un sencillo casetonado y las del crucero presentan decoración de yesería de traza posterior a su construcción inicial (Collantes y Gómez 1999). Se desconoce cómo se cubría originariamente el tramo del crucero y, aunque González de León lo describe cubierto con una cúpula con linterna, es posible que tuviese otra bóveda vaída -similar a las de los brazos del crucero-, con óculo central y linterna, todo ello desaparecido y sin documentación que nos permita recrear su trazado. Decía Gastalver Gimeno, que: "Terminada la instalación del Archivo y ya en funciones sus servicios, nos sorprendió la amenaza de ruina de su airosa bóveda... pudimos acometer a nuestras expensas esta inesperada y costosa obra recientemente terminada" (Gastalver 1936). Se refería, sin duda, a la bóveda del crucero.

Muy característico del genial arquitecto cordobés afincado en Sevilla, es la espadaña montada sobre el muro de saliente del brazo meridional de la iglesia, que marca con su presencia la fachada de ésta que asoma a la calle Feria y a la actual Plaza de Montesión (De la Banda 1974). Se trata de un campanario con dos cuerpos superpuestos. El inferior, que cuenta con dos arcos, queda enmarcado por tres columnas dóricas. Se corona por un entablamento donde

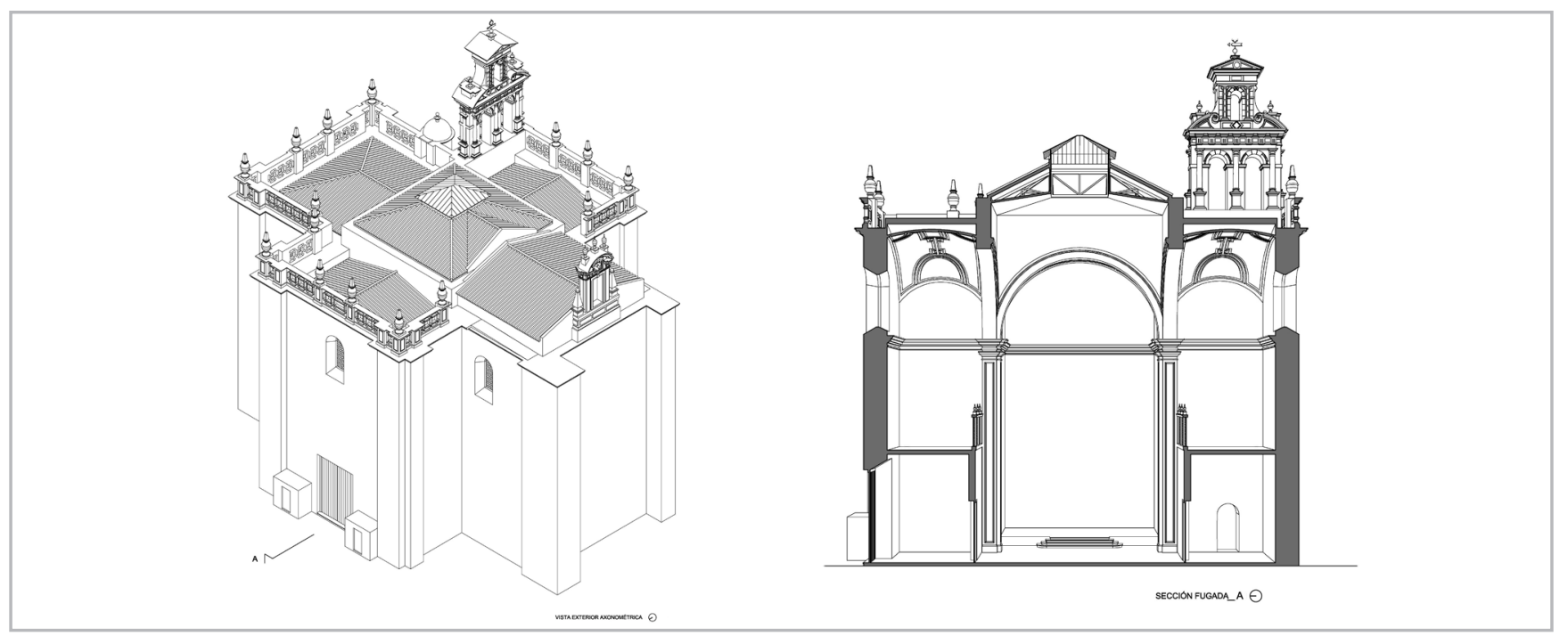

Figura 2.- Volumetría exterior de la iglesia y sección fugada A-A’. Estado previo a las intervenciones. Dibujos FJOG y PBO. 
se alternan triglifos y metopas, y se remata con un frontón curvo partido cuyas cornisas acaban en sendas volutas. El segundo cuerpo presenta un único arco, flanqueado por pilastras jónicas, coronado por un frontón triangular.

Toda la cabecera fue completada trasdosando los abovedamientos y rematando las cornisas exteriores con antepechos calados muy del gusto del arquitecto cordobés al que se atribuye su autoría. La nave de los pies de la iglesia se terminó ya en el siglo XVII, cubriéndose con armadura y tejado ventilado por un gran buhardillón que hoy ha quedado exento a modo de espadaña. Esta segunda espadaña es la que Matilde Fernández Rojas describe erróneamente como labor de cantería. Se trata de una obra de finales del siglo XVII o principios del XVIII realizada con ladrillo y cerámica. La iglesia prescinde, en este tramo de los pies, de los antepechos pétreos calados que se conservan en el resto de sus brazos. Esto podría responder a que quedó inacabada o dañada tras el terremoto de Lisboa de 1755. Esa, además, sería la razón por la cual se realiza en dicho tramo una cubierta de tejas sobre armadura leñosa, frente al resto de las cubiertas, en las que sus tejados se trasdosan directamente sobre las bóvedas [Figura 2].

\section{El archivo de protocolos notariales en la iglesia de montesión a partir de 1927}

El Archivo de Protocolos Notariales de Sevilla es una de las fuentes principales para investigar una parte fundamental de la historia de la ciudad, en todos sus rasgos y manifestaciones, desde las relaciones familiares a las económicas. En sus cláusulas testamentarias se traslucen ideologías, o simplicidades de la vida cotidiana, que conforman, en su aparente sencillez, los hilos que han ido tejiendo nuestra intrahistoria. Dicho archivo se nutre de todos los documentos públicos autorizados por cada uno de los notarios del distrito de Sevilla, cumplida ya una primera etapa de permanencia en la propia notaría donde se formalizan (Aguilar 1995).

En tiempos pretéritos, fue frecuente concertar en escrituras notariales cualquier relación interpersonal. Así, por ejemplo, se formalizaron contratos de aprendizaje; encargos de obras artísticas -pictóricas o escultóricas-, que solían especificar características, precios y plazos de entrega, lo que ha posibilitado atribuir la autoría a muchas de ellas, incluyendo numerosas obras de la imaginería de nuestra Semana Santa sevillana. En consecuencia, el de los protocolos notariales es un conglomerado vivaz y abigarrado de datos y sucesos, que se alinean con espontaneidad en los anaqueles de sus archivos. El conjunto de documentos que lo conforman ha tenido una vida azarosa a lo largo de su historia, e incluso se utilizaron para construir barricadas defensivas durante la invasión francesa.

Fue en el pasado siglo, concretamente en 1927, cuando el Colegio Notarial de Sevilla adquirió la iglesia del extinguido convento dominico de Montesión, abandonada y derruida en parte tras la desamortización de Mendizábal. A partir de entonces, se efectuaron las obras pertinentes cubriendo con una montera el tramo del crucero, cuya bóveda amenazaba ruina, y dándole acceso directo a la calle Feria mediante un cuerpo añadido al que se le dotó de una portada pétrea de sabor clasicista. También se construyó una sala de investigadores y las tres tribunas labradas sobre los pies de la iglesia y los dos brazos del crucero, a fin de aumentar la capacidad y número de las estanterías de madera donde se archivaban los volúmenes de protocolos. Las obras de adaptación para albergar el Archivo de Protocolos Notariales fueron dirigidas por el arquitecto D. José Gómez Millán, inaugurándose solemnemente el día 6 de octubre de 1927 (Gastalver 1936).

Según se recogía en la memoria de la Fase $1^{\text {a }}$ del Proyecto Básico y de Ejecución de Restauración de la Iglesia del Exconvento Dominico de Montesión y Sistematización del Archivo de Protocolos Notariales de Sevilla, en la década de los sesenta, el edificio, un tanto abandonado a su suerte, fue víctima de los temporales de lluvia y los estragos del tiempo, produciéndose fuertes goteras en sus cubiertas, especialmente por la montera acristalada que sustituyó a la bóveda central del crucero. No menos importantes eran las humedades de capilaridad, en parte debidas a defectos del alcantarillado, en parte consecuencia de la ausencia de soleras bajo los pavimentos -dispuestos directamente sobre el terreno-, y que, bajo el peso de las estanterías, se habían partido transmitiendo al ambiente las humedades del elevado nivel freático del suelo sevillano. Una invasión de termitas procedentes del subsuelo había penetrado a través de los pies derechos de dichas estanterías, afectando no solo a la madera, sino también a la celulosa del papel de los protocolos humedecidos por la lluvia.

Tanto para garantizar la conservación de tan importante legado monumental como para colaborar en la formación del nuevo Archivo Histórico Provincial, se suscribió un acuerdo entre el Colegio Notarial de Sevilla y la Dirección General de Archivos, por el que se almacenaba el núcleo más importante de legajos, hasta los últimos cien años, en el edificio de los antiguos Juzgados Municipales en la calle Almirante Apodaca, quedando los protocolos recientes depositados en el Colegio Notarial. Al mismo tiempo se planteaba la urgente necesidad de habilitar la mayor capacidad posible para acoger los protocolos históricos de otras ciudades de las provincias de Andalucía Occidental -Cádiz, Córdoba, Huelva y Sevilla- que dependen del Colegio Notarial hispalense. En 1998 se propuso una restauración profunda que habría de combinar el respeto a la estructura original de la antigua iglesia, dotándola de los medios técnicos necesarios para un archivo moderno.

El proyecto redactado por el arquitecto Rafael Manzano Martos, en orden a su ejecución, se dividía en dos fases fundamentales [Figura 3]. En la primera, desarrollada entre 1998 y 2000, se realizaba la edificación destinada a almacenamiento principal -silo principal- con independencia del templo, así como la vivienda y el coro 


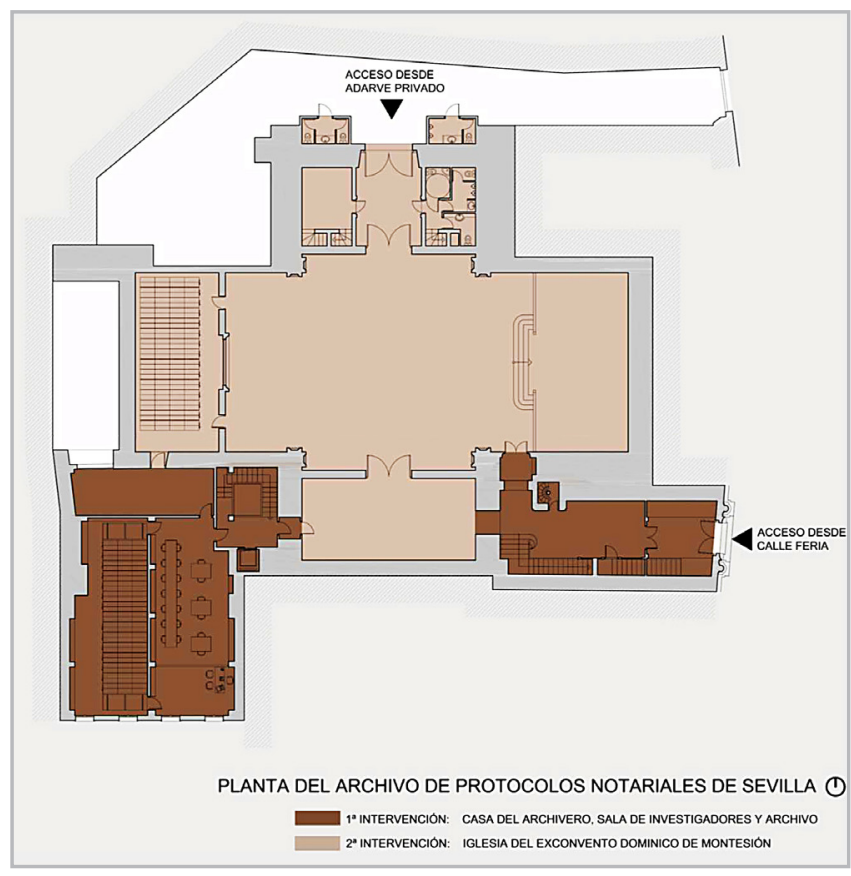

Figura 3.- Fases de intervenciones en la restauración del Archivo de Protocolos Notariales de Sevilla. Estado proyectado. Dibujo de FJOG y PBO.

bajo del brazo de mediodía. Realizada esta operación, se trasladaba todo el archivo, almacenado en las naves de la iglesia, a su lugar definitivo [Figura 4], liberando el edificio eclesial para su total restauración, en una segunda fase de actuación, en la que también se ejecutaría el silo del brazo oeste y su conexión con el archivo principal.

La primera fase del proyecto contemplaba la nueva construcción del silo principal, con cuatro plantas de escasa altura, resuelto con estructura mixta -metálica y hormigón armado-, dotado de su propia escalera y un montacargas. Este edificio ocupa las antiguas dependencias, carentes de valor artístico y escasa calidad constructiva, situadas en el ángulo suroeste de la iglesia y que, antes de las intervenciones, se destinaban a sala de investigadores, una destartalada escalera y parte de la vivienda del conserje.

El nuevo silo proyectado tiene capacidad para albergar prácticamente todos los volúmenes acumulados en la iglesia. No obstante, se proponía destinar a archivos, acondicionándolos debidamente y como silos menores, la tribuna del coro meridional y la nave de los pies de la iglesia. Estas áreas, en sus dos plantas, quedarían enlazadas con el silo principal, y en ellas se recogería el espacio necesario para la previsión de crecimiento del volumen de protocolos.

Esa primera fase se complementaba construyendo en el vestíbulo, trazado en el segundo cuarto del siglo XX por D. Vicente Traver y Tomás, una escalera para dar acceso, en su planta alta e independiente del archivo, a la vivienda del conserje y custodio del mismo (Manzano 1998). Para ello, se precisaba dividir esa planta alta con un entresuelo, dado que su altura lo permitía.

Quedaba así libre la nave central de la iglesia, que pretendía destinarse a salón de actos culturales o conciertos, así como espacio eclesiástico para celebrar las fiestas patronales. Se proyectaba la decoración de la iglesia con los grandes cuadros cedidos por el Museo de Bellas Artes de Sevilla al Archivo de Protocolos Notariales, que fueron trasladados a este lugar hace años. Se depositaron aquí, en tiempos de la posguerra española, una serie de cuadros, considerados de menor valor artístico a los expuestos en el museo y en pésimas condiciones de conservación (Manzano 1998). Algunos de ellos eran copias, como la Inmaculada Concepción "La Colosal", cuyo original puede admirarse hoy en la iglesia del exconvento de la Merced Calzada, actual Museo de Bellas Artes de Sevilla.

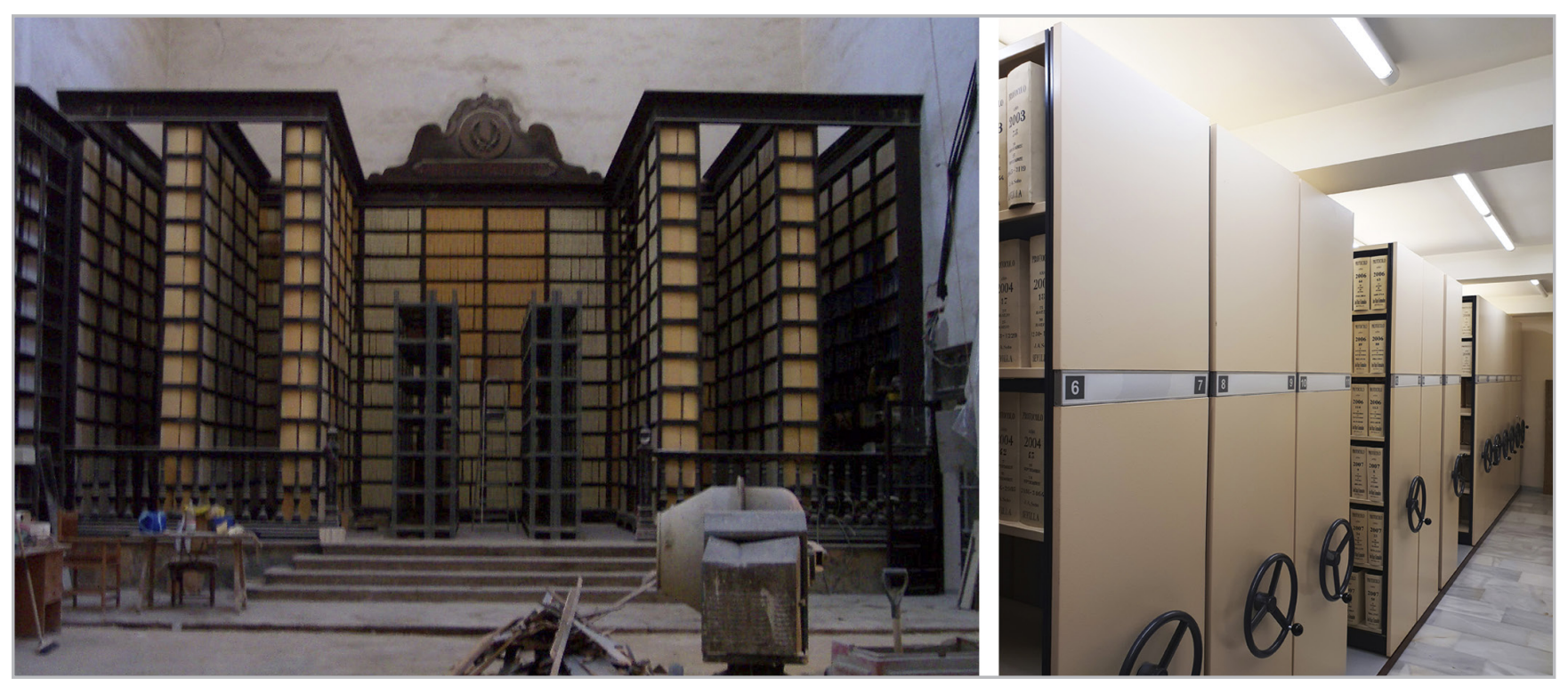

Figura 3.- Protocolos en el presbiterio de la iglesia, que fueron trasladados, y archivadores en el nuevo edificio proyectado para su almacenamiento -silo principal-. Fotografías PBO. 


\section{La restauración de la iglesia}

El viajero inglés Richard Ford, en su Hand-Book for Travellers in Spain, advertía que el enjalbegamiento, con la fatal cal de Morón, era la maldición de Sevilla (Rodríguez 2007). Fue propósito fundamental de la restauración, eliminar emparchados, revestidos y encalados añadidos en épocas posteriores, para recuperar las texturas de sus magníficas fábricas latericias y pétreas [Figura 5]. Se trataba, en definitiva, de redescubrir las esencias materiales de obra tan singular, poniendo en valor sus fundamentos estructurales originales.

La restauración eclesial, aun contenida administrativamente en una misma fase de intervenciones -la segunda-, hubo de ceñirse, por razones presupuestarias, a varias etapas organizadas por zonas. El criterio de actuación venía marcado por un recorrido que se iniciaba en los pies de la iglesia y concluía en su presbiterio. Siguiendo el mismo itinerario temporal, seguidamente se analiza la restauración por áreas de intervención.

\section{-Intervenciones en los pies de la iglesia}

Se rehabilitó el coro de los pies [Figura 6], construyendo una nueva entreplanta apoyada sobre losa de hormigón, con pilares y vigas metálicas como estructura independiente a la preexistente, para aumentar la capacidad de almacenamiento de protocolos, y conectando los dos niveles superiores -nueva entreplanta y tribuna-, con el silo principal edificado en fase anterior. Ya en esa primera campaña, se había realizado la apertura mural de conexión del coro, en su planta baja, con el nuevo edificio de archivo.

Para el diseño de la fachada interior de los pies, se mantuvo hacia la iglesia el carácter de coro bajo conventual, muy hermético, empleando celosías que recuerdan la clausura monástica para impedir vistas a los archivadores tipo "compactus"que aquíse almacenan. A eje dela composición en la planta inferior, se dispone un gran hueco central con enrejado tupido de madera, a cuyos laterales se sitúan sendas puertas de acceso, con recercos y flanqueadas por pilastras toscanas, como una simplificación del dórico empleado en el orden mural apilastrado del templo. En la entreplanta, marcada de la anterior por una imposta, se disponen, a eje vertical de las puertas inferiores, dos óculos ovalados, también cerrados con celosías y en plano rehundido respecto a sus enmarcados rectangulares. Ocupa el centro, sobre un plano paramental sobresaliente, otro rehundido diseñado para albergar, restaurada para la ocasión, la obra pictórica la Multiplicación de los panes y los peces, procedente del Museo de Bellas Artes de
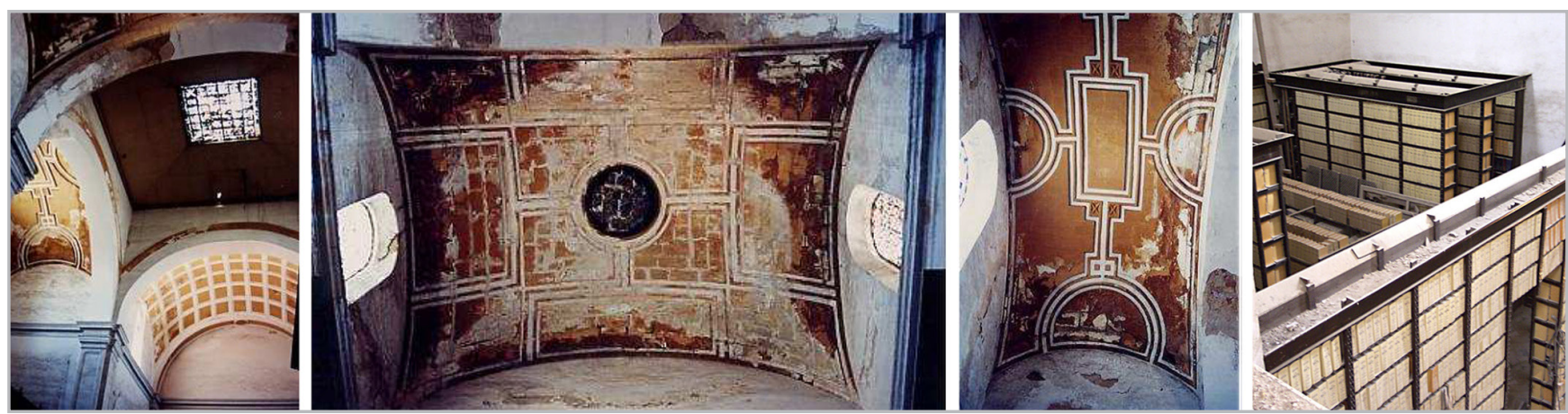

Figura 5.- Imágenes del estado anterior a las intervenciones en la iglesia. Fotografías de PBO.
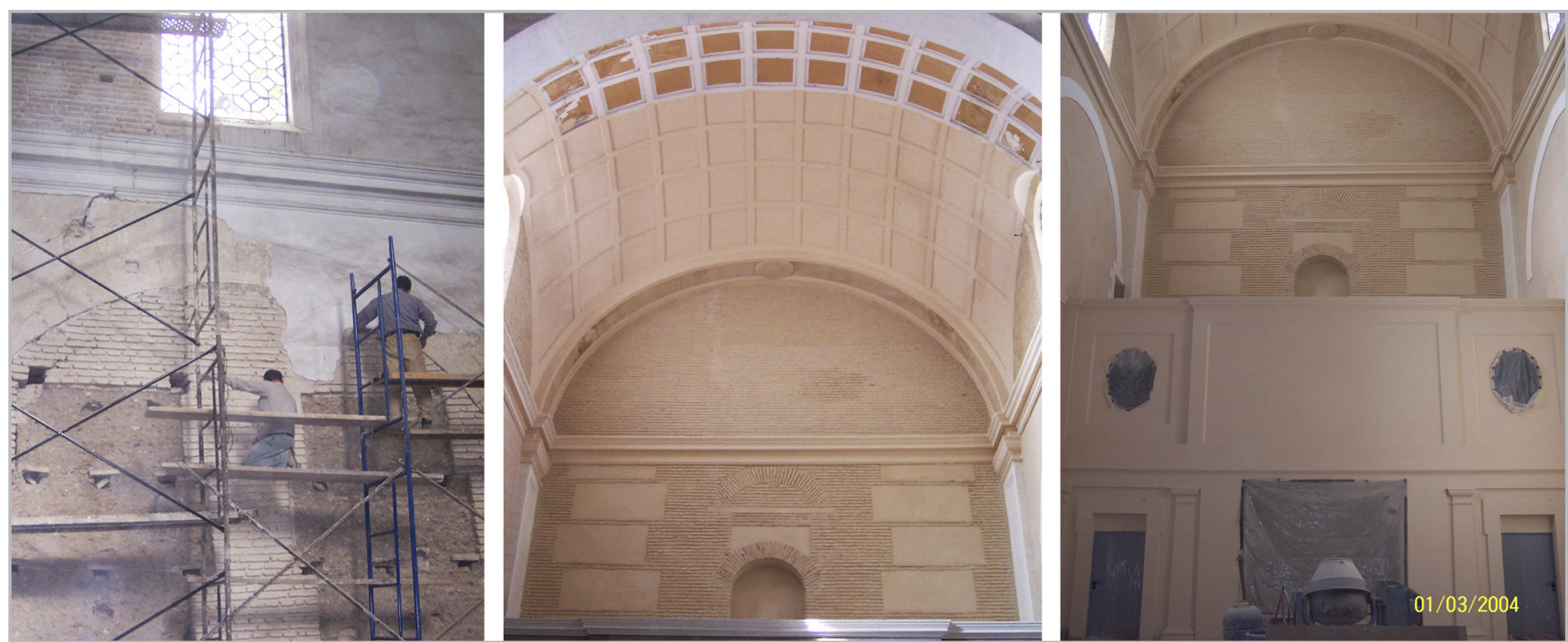

Figura 6.- Intervenciones en los pies de la iglesia. Fotografías de PBO. 
Sevilla donde se encontraba almacenada. Se trata de una versión de época del conocido cuadro del mismo tema de Bartolomé Esteban Murillo, encargada por Miguel de Mañara como recordatorio de las obras de misericordia corporales, y que se conserva en la iglesia del Hospital de la Santa Caridad de Sevilla.

Se iniciaban, además, los picados de los revestimientos de las fábricas de ladrillo que conforman los paramentos de esta zona, retacando con piezas de tejar de apariencia similar sus antiguos mechinales, y empleando morteros de cal en sus llagueados, concebido el conjunto ahora como fachada interior de obra vista. Al picar los revestidos murales, aparecieron varios cajones de tapia que fueron enlucidos con los mismos morteros de cal empleados para los llagueados de los ladrillos. Igualmente, se procedía a la limpieza de sus elementos pétreos, eliminando los emparchados en los cajeados de sus arcos fajones. Continuaban las tareas con los enjalbegados de arcos, cornisas y bóveda casetonada, empleando jabelgas aditadas para obtener la coloración pretendida en cada uno de esos elementos. Se repusieron, reparadas y adaptadas a la nueva fachada, las antiguas celosías del coro alto que permiten ocultar otro cuerpo de archivadores. Con la limpieza, repasos generales y reposiciones necesarias en los tejados que cubren la nave de los pies, se concluían las actuaciones en este área.

\section{- Intervenciones en los brazos del crucero}

Seguidamente, se iniciaron los trabajos de rehabilitación de los coros laterales [Figura 7], introduciendo un entresuelo destinado a uso administrativo en ambos extremos del ala norte, con sus respectivas escaleras -solo una de ellas se prolongó hasta la tribuna-, al tiempo que se consolidaba estructuralmente el forjado de dicha tribuna. En el brazo de mediodía, se trasdosó un nuevo forjado al alfarje preexistente, para garantizar su capacidad portante, en previsión de las cargas estimadas para los archivadores de protocolos.

Se resolvieron simétricamente los frentes de ambos coros, abriendo un hueco en el frente meridional, idéntico al existente en el brazo del evangelio, conectando así el de la epístola con el espacio principal del templo. En ambos huecos se han dispuesto recercados, prolongando sus fajas verticales para la formación de pilastras hasta la cornisa superior de remate. A eje del dintel de la puerta, se incluye una clave moldurada sobre la que se sobrepone un rehundido ovalado para insertar una celosía de madera. Sendas pilastras, una a cada extremo, completaban la composición de los frentes analizados. También en los coros altos laterales fueron restituidas sus antiguas celosías.

Prosiguieron los picados de revestimientos en paramentos de ladrillo, retacando ausencias en antiguos mechinales y reponiendo pérdidas en puntos de deterioros significativos

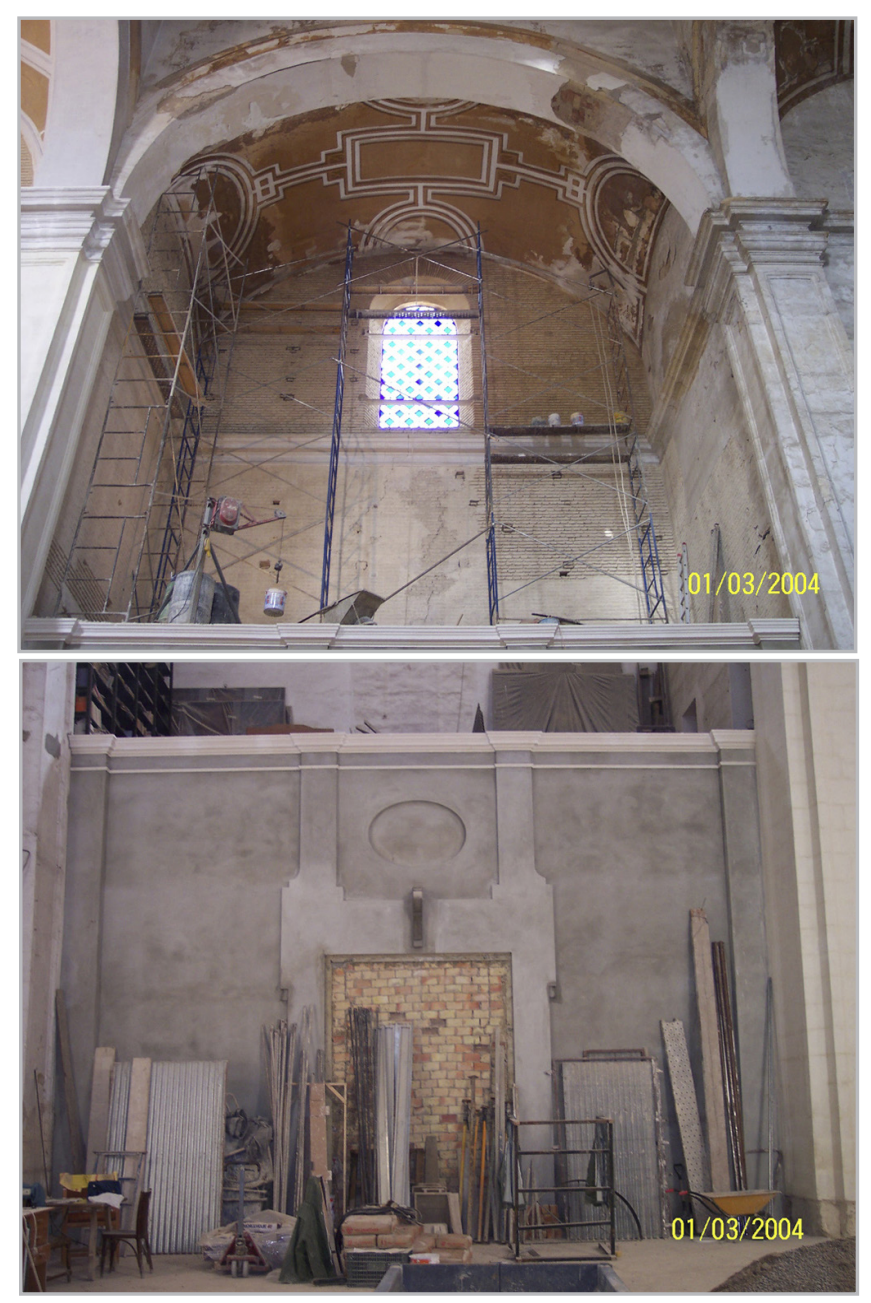

Figura 7.- Intervenciones en los brazos laterales. Fotografías de PBO.

de material. Limpiezas generales y eliminación de aditamentos en elementos pétreos, precedían a los enjalbegados de arcos, cornisas y bóvedas de yesería. Las reparaciones de las cubiertas que gravitan sobre los brazos cerraban las previsiones presupuestarias para la zona.

\section{— Intervenciones en el crucero}

La tercera campaña de intervenciones en la iglesia contemplaba la construcción de la bóveda del crucero, desmontando la tablazón colocada, según el testimonio de Gastalver, recién terminada la instalación del Archivo y ya en funciones sus servicios. Para colgar la nueva bóveda de escayola se reutilizaría la estructura metálica que sustentaba el entramado de madera eliminado. El arquitecto Rafael Manzano, consciente de que González de León describía en el crucero una cúpula con linterna, propuso, por diversas razones, una bóveda vaída, como las demás del conjunto, con óculo circular central, cuya vidriera seguía el diseño del resto de los ventanales que dan luz al templo [Figura 8]. Si bien esta fue la versión finalmente aceptada, hubo alguna propuesta que incluía una linterna en su diseño. Siguiendo la metodología general de actuaciones, se revisaron sus cubiertas, con limpieza 


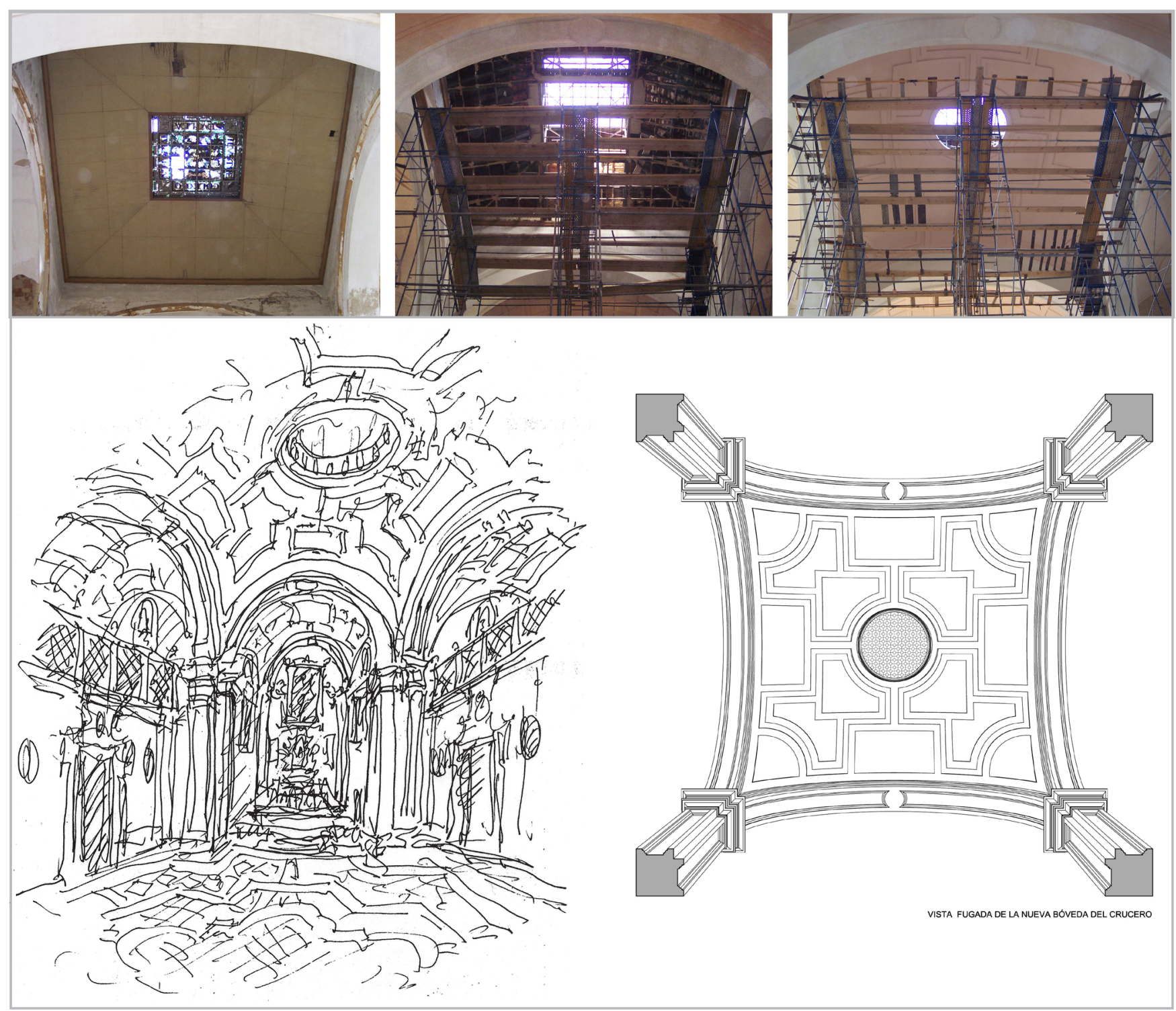

Figura 8.- Intervenciones en el crucero. Fotografías de PBO. Dibujos de RMM, FJOG y PBO.

general y reposición de piezas defectuosas, reservando parte del presupuesto para las reparaciones necesarias en la montera central, de cuatro paños acristalados con estructura metálica.

Desmontados los suelos, muy deteriorados por las humedades, se ejecutó una solera armada sobre la que apoyaría el sistema de andamiaje necesario, de mayor altura, para la ejecución de la bóveda. Así mismo, se retiraron los restos del antiguo zócalo cerámico del siglo $\mathrm{XVI}$.

\section{— Intervenciones en el presbiterio}

Como en el caso de la nave del crucero, se practicó una excavación en el presbiterio para incluir una solera armada, mejorando el aislamiento con el terreno y donde apoyaría el andamiaje necesario para las obras en la cabecera [Figura 9]. Durante el transcurso de las excavaciones, se hallaron la placa conmemorativa que testifica el enterramiento de la fundadora del convento en su capilla mayor, así como el escudo heráldico de $D^{a}$. Mencía labrado en mármol de gran calidad. Ambas piezas, perdidas en tiempo incierto y de las que teníamos noticias por Gestoso, fueron colocadas en los muros del presbiterio una vez restaurados.

Al igual que en el resto de la iglesia, se llevó a cabo el picado de paramentos dejando a cara vista y libre de cal los ladrillos de su fábrica. Los elementos de ornamentación pétrea se sometieron a tratamientos de limpieza, aplicándoles posteriormente los enjalbegados correspondientes. Similar proceso se siguió con la bóveda que cubre este tramo. Limpiezas generales y reparaciones puntuales en los tejados garantizaban la estanqueidad de sus cubiertas.

La decoración de escayola diseñada para enmarcar los cuadros almacenados en el antiguo Convento de la Merced Calzada, cerraban las partidas presupuestarias 

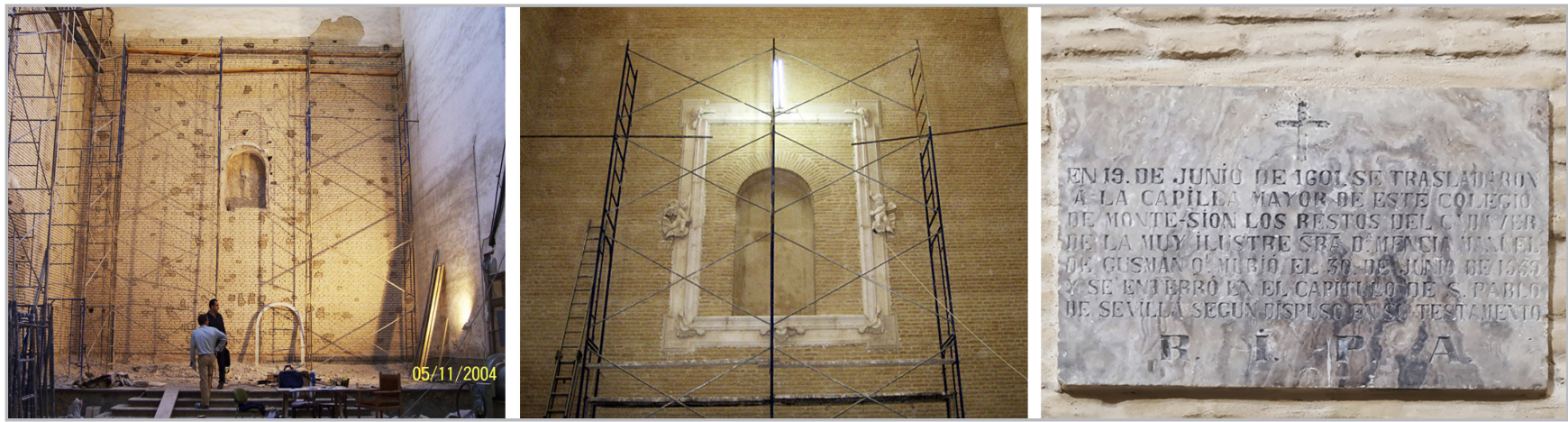

Figura 9.- Intervenciones en el presbiterio. Fotografías de PBO.

destinadas para la restauración de los paramentos absidales. Presidiendo el testero principal, aparece una copia de la Inmaculada Concepción "La Colosal" de Murillo, cuyo original, hoy en el Museo de Bellas Artes, procede del desaparecido convento de San Francisco en Sevilla. Sobre él se ha situado El sueño de San José, una obra decimonónica de escasa calidad, en cuyo fondo aparece una Inmaculada, mostrada por un ángel al santo, que constata la persistencia del murillismo en la pintura sevillana en fecha tan tardía. Para los paños laterales se han reservado dos obras de dimensiones similares. En el lado del evangelio, Nuestra Señora de la Correa, óleo de calidad excelente donde se representa la aparición de la virgen, con un ángel y San Juan Bautista, a San Agustín y Santa Mónica. Se repite así la fórmula que recuerda a la Virgen entregando el rosario a Santo Domingo de Guzmán, fundador de la orden de los dominicos a la que pertenecía el convento. En el de la epístola, un hermosísimo Pentecostés que recoge la consabida escena descrita en el Acta Apostolorum de San Lucas. Lo firma Ludovicus -no aparece apellido-, y está fechado en 1626. Se desconoce su procedencia, $y$, sin duda, es de máxima calidad pictórica y de la Escuela Napolitana. Todos los cuadros citados fueron restaurados con cargo a los presupuestos del Colegio Notarial de Sevilla con motivo de las obras en el edificio.

\section{- Otras intervenciones}

Se incluyen en este apartado la reposición de la solería de la nave central y el presbiterio, resuelta con mármoles blancos, amarillos y rojos, así como el zócalo de piedra colocado en el perímetro del interior de la iglesia, que sustituía al viejo alicatado cerámico anterior muy deteriorado.

En una alacena del coro bajo del brazo de la epístola, se instaló, tras su restauración, un altar barroco del siglo XVIII, en cuya hornacina central se ha colocado una imagen de San Juan Evangelista, patrón de los notarios debido al testimonio que nos ofrece al término de su Evangelio: "Este es el discípulo que da testimonio de estas cosas y el que las escribió, y sabemos que su testimonio es verdadero".

También se acometieron obras de mejora en los añadidos colaterales a la puerta de la iglesia en el nártex de acceso por el adarve privado, para dotarlos de cierta dignidad. Estas construcciones constituyen los servicios para uso de la Hermandad de Montesión, cuya capilla ocupa el ángulo nordeste del templo dominico. Al mismo tiempo se ornamentaba con un sencillo recercado la puerta de acceso a la iglesia. Se eliminaron revestimientos y encalados de la fachada al callejón, dejando a la vista su fábrica de ladrillo, en la que apareció el despiece del dovelaje de un arco sobre el dintel de la citada puerta.

Entre las últimas tareas se destacan las reparaciones y enjalbegados en las zonas más deterioradas de las fachadas exteriores de la iglesia, en las que no se incluyeron, por razones presupuestarias, ni la intervención en su espadaña pétrea, ni la de sus magníficos antepechos calados. Todo ello habría supuesto la culminación de la restauración del templo, devolviendo a la ciudad una mejor imagen de los volúmenes emergentes de tan singular edificio sevillano.

\section{Conclusiones}

Este trabajo ofrece los resultados de un minucioso análisis de la restauración llevada a cabo en la iglesia del antiguo convento dominico de Montesión. Se describe y detalla dicha intervención, aportando nueva documentación gráfica, poniendo en valor el único vestigio que se conserva de este conjunto monumental, fundado por Doña Mencía Manuel de Guzmán y construido en el siglo XVI. Tras ser desamortizado en 1835, sufrió los avatares del tiempo hasta que en 1927 el Colegio de Notarios de Sevilla adquirió la propiedad de la iglesia, a fin de adecuarla, junto a otras de sus construcciones anexas, para albergar el Archivo de Protocolos Notariales de Sevilla.

Hacia 1970 el edificio presentaba un precario estado de conservación a causa de las importantes humedades que padecía, procedentes tanto de las filtraciones de aguas por sus cubiertas como de la capilaridad del terreno. Las estanterías de madera dispuestas en las naves de la iglesia para almacenar los protocolos notariales, sufrían ataques de xilófagos que no solo afectaron a la madera, sino también a la celulosa del papel de los protocolos humedecidos 
por las lluvias. Para garantizar la conservación de tan importante legado monumental, en 1998 se propuso una restauración profunda que habría de combinar el respeto a la estructura original de la antigua iglesia, dotándola de los medios técnicos necesarios para un archivo moderno.

El proyecto, redactado por el arquitecto Rafael Manzano Martos, proponía dos fases de intervenciones. En la primera (1998-2000), se construía el silo principal anexo a la iglesia. Realizada esta operación, se trasladaba todo el archivo, almacenado en las naves del templo, a su lugar definitivo, liberando el edificio eclesial para su total restauración en una segunda fase de actuaciones (20022008). Las intervenciones en la iglesia se resolvieron, por razones presupuestarias, en varias etapas organizadas por zonas.

En general, se eliminaron emparchados, revestidos y encalados añadidos en épocas posteriores, para recuperar las texturas de sus magníficas fábricas latericias y pétreas, poniendo en valor los fundamentos estructurales originales. Las reparaciones en sus cubiertas y la ejecución de una solera para mejorar el aislamiento con el terreno, contribuían a evitar las humedades que afectaron al edificio y a su valioso contenido documental. Tanto en el coro de los pies como en los brazos, se mantuvo en sus nuevas fachadas hacia la iglesia el carácter conventual, empleando celosías que recuerdan la clausura monástica para impedir vistas a los archivadores que allí se almacenaron. Una de las actuaciones más singulares fue la ejecución de la bóveda del crucero, resuelta vaída como las demás del conjunto, con óculo circular central y cuya vidriera sigue el diseño del resto de los ventanales que dan luz al templo.

Durante las intervenciones en la cabecera, se localizaron la placa conmemorativa del enterramiento de la fundadora en la capilla mayor del convento y su escudo heráldico labrado en mármol de gran calidad. Ambas piezas fueron colocadas en los muros del presbiterio. Completaban las obras en el interior de la iglesia la decoración proyectada para enmarcar los cuadros almacenados en el antiguo Convento de la Merced Calzada, restaurados para la ocasión con cargo al colegio notarial. El estado de conservación actual en general es bueno, si bien se han detectado puntualmente humedades de capilaridad ascendentes en zonas donde, por razones presupuestarias, no se aplicaron barreras anticapilares. De este modo, se ha recuperado el edificio, pudiendo percibirse su trazado cruciforme y los abovedamientos del conjunto, destinándose ahora a salón de actos culturales o conciertos, así como espacio eclesiástico para celebrar las fiestas patronales [Figura 10].
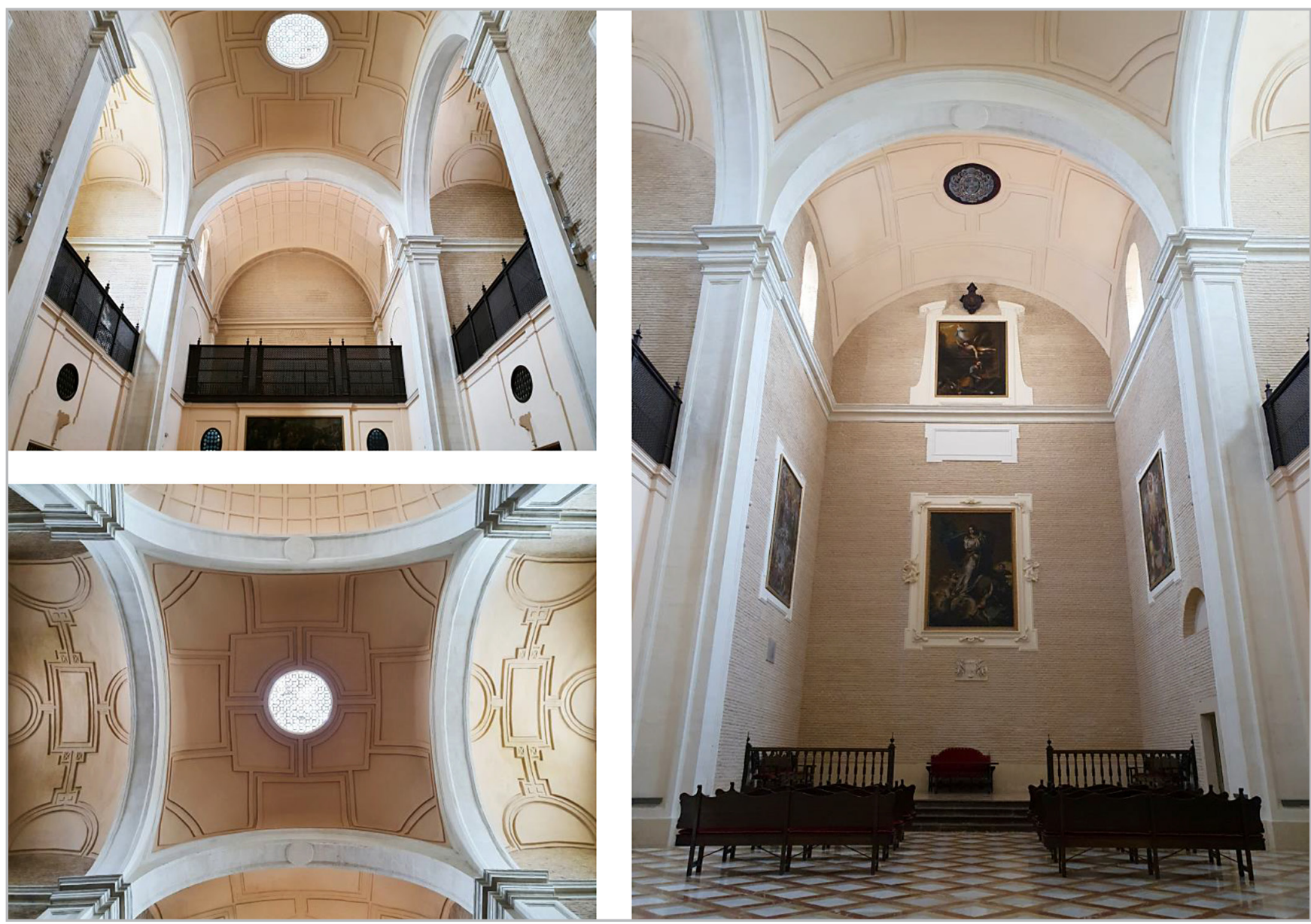

Figura 10.- Imágenes de la iglesia restaurada. Fotografías de PBO. 
Señalar, por último, que las actuaciones analizadas han promovido la conservación de una de las iglesias más singulares de la ciudad, atribuida al arquitecto que coronó la Giralda con su cuerpo de campanas; también la de los bienes muebles que hoy la decoran, como son los cuadros restaurados para la ocasión y cedidos al Colegio de Notarios hispalense por el Museo de Bellas Artes de Sevilla; y, finalmente, la del propio Archivo de Protocolos Notariales, cuyos documentos centenarios constituyen una de las fuentes más genuinas para el conocimiento de la historia de la ciudad, así como de las personas que durante siglos dejaron huella en la vida de nuestro pueblo.

\section{Referencias}

AGUILAR GARCÍA, M. (1995). El colegio notarial de Sevilla: una casa al servicio de la corporación. Ilustre Colegio Notarial de Sevilla. Sevilla.

COLLANTES DE TERÁN DELORME, F.; GÓMEZ ESTERN, L. (1999). Arquitectura Civil Sevillana. Área de Cultura. Excmo. Ayuntamiento de Sevilla. Editorial Castillejo. Tercera edición. Sevilla.

DE LA BANDA Y VARGAS, A. (1974). El arquitecto andaluz Hernán Ruiz II. Diputación Provincial. Sevilla.

FERNÁNDEZ ROJAS, M. (2008). Patrimonio Artístico de los conventos masculinos desamortizados en Sevilla durante el s. XIX. Diputación de Sevilla, 226-227.

GASTALVER GIMENO, J. (1936). El Archivo de Protocolos de Sevilla [Discurso leído ante la Academia Sevillana de Buenas Letras en su recepción pública el día 26 de enero de 1936]. Boletín de la Real Academia Sevillana de Buenas Letras. Sevilla.

GESTOSO Y PÉREZ, J. (1897). Sevilla Monumental y Artística. Ayuntamiento de Sevilla. Sevilla, 64-66.

GONZÁLEZ DE LEÓN, F. (1844). Noticia artística, histórica y curiosa de todos los edificios públicos, sagrados y profanos, de ésta muy noble, muy leal, muy heroica e invicta ciudad de Sevilla, y de muchas casas particulares con todo lo que le sirve de adorno artístico, antigüedades, inscripciones y curiosidades que contienen. Sevilla, Vol. I.

MANZANO MARTOS, R. (1998). Proyecto Básico y de Ejecución de Restauración de la Iglesia del Exconvento Dominico de Montesión y Sistematización del Archivo de Protocolos Notariales de Sevilla (1 ${ }^{\text {a }}$ Fase). Sevilla.

MANZANO PÉREZ DE GUZMÁN, J.; BARRERO ORTEGA, P. (2012). "La Iglesia del Convento Dominico de Montesión en Sevilla. Una posible atribución a Hernán Ruiz II a partir de recientes levantamientos". Revista EGA. 19: 78-89. https://doi.org/10.4995/ ega.2012.1360

RODRÍGUEZ BARBERÁN, J. (2007). Richard Ford y Sevilla (18301833) Una Antología. Clásicos sevillanos. Sevilla, 104.

\section{Autor/es}

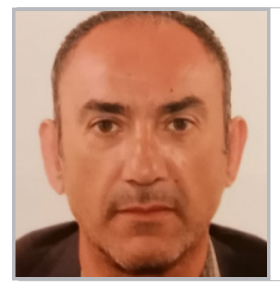

Pedro Barrero Ortega

pbarrero@us.es

Universidad de Sevilla

https://orcid.org/0000-0002-0751-8713

Pedro Barrero Ortega es Doctor Arquitecto y Profesor Asociado de la Universidad de Sevilla. Pertenece al grupo de investigación "HUM976. Expregráfica. Lugar, Arquitectura y Dibujo". Su extensa actividad profesional se ha desarrollado durante décadas, junto a Rafael Manzano Martos, en variadas intervenciones en patrimonio arquitectónico. Es autor de diversos artículos en dicho ámbito desde el punto de vista de la expresión gráfica arquitectónica.

Artículo enviado el 01/06/2021 Artículo aceptado el 25/11/2021

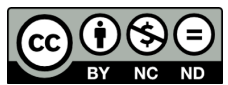

https://doi.org/10.37558/gec.v21i1.1010 